\title{
Are Out-of-Body Experiences Evidence for Survival?
}

\author{
Susan Blackmore \\ Brain and Perception Laboratory \\ University of Bristol \\ Bristol, England
}

\begin{abstract}
This paper argues that for both theoretical and empirical reasons the out-of-body experience (OBE) cannot provide evidence for survival of death. Definitions of the $O B E$ are discussed and typical features described, including the fact that OBEs often convince people of survival. OBEs can provide survival evidence only if it can be shown that (1) something leaves the body during an OBE, and (2) that that "something" could survive the death of the body. There are serious difficulties in conceiving of anything that could perform the movement, perception, and in formation transfer required in an OBE. The evidence suggestive of something leaving the body includes (a) perception at a distance during OBEs, (b) the detection of a double or astral body, and (c) near-death experiences. That evidence is reviewed and argued to be inconclusive. A psychological theory of the OBE is presented in which the out-of-body world is seen as constructed by imagination from the cognitive map. It is argued that this theory provides greater hope for understanding mystical and related experiences.
\end{abstract}

It may be rather rash of me to ask whether OBEs are evidence for survival, not because the answer is so obviously "No," nor even because it is "Yes" or "Maybe," but because some of the issues raised are so problematic. Nevertheless I think it is an important question because it forces us to confront the theoretical obstacles involved and the inadequacies of the evidence. Having considered these problems, I shall argue that it is far more profitable to look at the OBE in quite a different way.

This question has a long history and has never been satisfactorily answered. When the Society for Psychical Research was founded over a hundred years ago, the major motivation behind it was the quest for evidence for survival. The subject has since had declines but now seems to be coming back into vogue. Both then and now OBEs have been considered as part of that evidence. Indeed, many writers seem to take it for granted that the occurrence of an $O B E$ 
implies both the existence of something that leaves the body, and the possibility of that "something" surviving death (see, e.g., Mitchell, 1981; Badham and Badham, 1982; Rogo, 1983). That view has of course been challenged (e.g., Noyes and Kletti, 1976; Siegel, 1980), but why has it become so popular in the first place?

From time to time people claim to have seen things at a distance during an OBE. That is therefore "paranormal" and provides an apparent justification for OBEs being considered to be "psychic experiences." However, I believe that by far the more important reason is that having an $\mathrm{OBE}$ so often persuades people of personal life after death.

The argument goes something like this: "I have been out of my body during life. Therefore 'I' am not my body. I can live without my body and therefore when it is dead I shall still live." In other words death is no more than an extended, or permanent, OBE. The argument is demonstrably false, but that does not detract from its power. It is strangely true that the persuasiveness of an argument need bear little relationship to its validity. The argument seems to be terribly convincing with very little justification.

What I hope to do here is to discuss briefly some logical and philosophical problems with relating OBEs to survival, to discuss some of the evidence bearing on their relationship, and finally to show why I believe there are far more interesting questions to ask about the OBE. But first I should say a little about the nature and definitions of the OBE.

It is almost impossible to describe a "typical" OBE because the experiences differ so very much. I shall therefore indulge in relating my own first OBE, as an example. This happened one evening in a friend's room in college at Oxford. I was very tired, had had a small amount of cannabis, and was lost in a pleasant imaginary tunnel of trees, when one of my friends quite unexpectedly asked me where I was. I suppose that should have seemed a silly question, since he could obviously see me; however, I struggled to answer and found myself apparently looking down on my own body from the ceiling. I watched as my own mouth opened and closed in telling him where I was. I seemed to have some sort of duplicate body "up there," and it was connected by a "silver cord" to the body. I could move at will, by thinking, and found that it was a delightful sensation to do so. It was not hard to leave the room, the building, and even Oxford, and I spent more than two happy and excited hours exploring that amazing state, and telling my friends all about it. At first I was sure I was seeing the actual room and surroundings, but later I seemed to 
be in what the occultists have long described as the "world of illusion" or a "thought-created world." Everything is biddable by thought, and the only limits seem to be what one can imagine.

Now I must emphasize that mine was not a "typical" OBE, but then none is. To give an idea of what most seem to be like, though, various figures are relevant. Surveys have shown that something like 10-20 percent of ordinary people claim to have had an OBE at some time in their lives, although extreme figures of 8 percent and 50 percent have been obtained with certain groups (see Blackmore, 1982a, 1982b, and 1982c for a review). As far as we can tell, people who have OBEs (OBErs) are not odd in any way. They are not more often male or female, are not cleverer, more educated, richer, more religious, or different in any very obvious way (see Green, 1968; Palmer, 1979; Kohr, 1980), nor do they show any special psychological profile (Gabbard, Twemlow, and Jones, 1982). Recent findings suggest that they may have slightly better spatial imagery skills and are better able to immerse themselves in experiences to the exclusion of the outside world (Irwin, 1981), but basically we can say that there is nothing odd about someone who has an OBE.

Some OBEs take place during stress, accidents, or operations. Others occur when a person is deeply relaxed or meditating, but some happen for apparently no reason at all. Most are fairly short. A minute is relatively long for an OBE. Perhaps the most interesting finding of modern case studies is that so few OBEs fit the classical astralprojection pattern. The doctrine of astral projection asserts that an $O B E$ is the result of the astral body being released from the physical body and taking "consciousness" with it. The two remain connected by a silver cord, at least as long as the body is alive, and the astral body can travel at will in the astral worlds. In view of that it is interesting to find that only about 20 percent of OBErs report having had another body. Most seem to be just a point or blob. And less than 5 percent have anything remotely like a silver cord (see Green, 1968; Osis, 1979; Blackmore, 1982a). Was my silver cord only the result of expectation? Whatever its origin, the facts seem to contradict the astral-projection model, which has to be stretched yet further to accommodate them. That means an already vague and elastic theory becoming even more so.

Another fact to note about the OBE is that what is seen varies widely. Many people see their own bodies, but that is not universal. Quite a few travel long distances, but many only glimpse their own room and the experience is over. A few, but I must emphasize that it is only a few, claim to have seen things at a distance that they 
could not possibly have known about, and finally, even fewer claim that they appeared as an apparition to someone else.

That may give some idea of the variety of OBEs, but what about their definition? I would define the OBE as an experience in which a person seems to perceive the world from a location outside of his physical body, or more simply as the experience of seeming to leave one's body. The definition is important, and those I have given are neutral regarding theories of the OBE. One might prefer to say that an OBE occurs when a person does leave the body, but that immediately raises awkward questions about what we mean by a person and so on. Also, if the definition assumes that something does leave the body, then not only is one presuming what has to be tested, but it also becomes impossible to know whether any particular $O B E$ is "genuine."

Several authors, notably Karlis Osis (1974) and Hornell Hart (1954), have tried to distinguish "genuine" or "bona fide" OBEs from others on the basis of whether any paranormal perception was involved. That attempt is clearly doomed. If we have learned anything in one hundred years of psychical research, it surely includes the fact that we can never be sure on any particular occasion whether any thing paranormal has occurred or not. We can therefore never be sure whether any OBE was "genuine" or not on that basis.

That is just one of the reasons why I prefer to stick with an experiential definition. We need not commit ourselves on that most important question of all, "Does anything leave the body in an OBE?" If we someday have an answer to that, or if we find some objective measure of whether someone is having an OBE or not, then we can easily change our definition accordingly.

of course the experiential definition carries costs. If someone says he has had an OBE, we have to believe him, since it is defined as an experience. That raises the important distinction, to which I shall keep referring, between what people say they saw in their OBEs and how they interpret what they saw. At a certain level the distinction breaks down, but for most discussion it is terribly important to make it clear. I make a general policy of always believing what people say about their experiences. If they say they flew over St. Paul's, then I believe that that was what they experienced. That is quite different from believing that any particular thing flew over St. Paul's. The latter is not implied by the experience, and it is what we have to find out. Does any thing actually travel in an OBE?

We may now tackle the question of what bearing the OBE has on the evidence for survival. There are two steps here. First is the 
question of whether anything leaves the body in an OBE. That question is crucial because if OBEs are to be considered evidence for survival, it is necessary (though not sufficient, of course) to show that something leaves the body. Second is the question of whether that something could survive the death of the physical body.

There are two major approaches to answering those questions. One involves logical and philosophical arguments; the other, empirical evidence. I shall consider each in turn.

First, why did I reject the argument from experience out of hand? The main reason is that it involves quite unwarranted leaps from what the experience feels like to a particular interpretation. Clearly, in most OBEs the body is alive and functioning during the experience, and it is unjustified to say that the "real me" was "out" or that it did not depend on the body. I know how much it feels as though the body is nothing, but that is no reason for assuming it is. I shall mention later cases in which the brain may not have been functioning, but for the most part it is clear that it could have been responsible for the experience. The big question becomes, can the whole experience be accounted for by imagination, memory, and so on, or does something actually leave the body?

The main problem to face is conceiving of anything that could do so. The "whatever it is" must not only be capable of leaving the body, but must be able to move, to perceive at a distance, and to transmit the results back to the body. That is a very tall order. If we conceive of some sort of pseudo-physical entity doing all that, then we must face all the problems of energy transmission from place to place, and movement and perception without detection.

W.A.H. Rushton (1976) pointed out one problem, that in order to see, the "double" must pick up light. If it picks up light, it must be opaque, and hence must be visible. In various forms that argument is compelling because perception necessarily involves interaction with the environment. Of course the interaction need not involve light, and one could postulate some kind of interaction that was hard to detect. Nevertheless, it should in principle be detectable. The problem may not be insoluble, but it is a real problem.

We must next explain how information gets from the distant entity back to the body, and that raises all the problems that psychical researchers and parapsychologists have been grappling with so unsuccessfully for so long.

To get away from those kinds of problems, many have preferred to argue that the double is an astral body and that it travels in the astral, not physical world. That maneuver leads to either of two 
suggestions. One may postulate an astral world that duplicates the physical and so face problems of communication between astral and physical (much like mind-body problems). Or one may have a kind of astral world with no connection with the physical. In that case OBEs could not involve travel in the physical world and can be seen as private fantasies. (As I shall try to show later, that may in fact be a more interesting result, but it is not what is usually meant by astral projection and does not really entail anything leaving the body.)

To escape from all of these problems, some people (see Rogo, 1978) have resorted to suggesting that what leaves the body is just consciousness, or just a perceiving point. However, it seems very hard to define consciousness in any way that allows it to do the job required in an OBE. Consciousness is not normally considered to be the kind of thing that has a location at all, and to expect it to be located outside of the body and capable of perceiving, moving, and so on is to distort any normally recognized notion of consciousness unacceptably far. The final option, of saying that all that leaves is a perceiving point, also fails. The point is defined only by where it is perceiving from. One of the very few things we know for certain about the $\mathrm{OBE}$ is that people often make errors in what they see. Whether they are sometimes correct is in dispute, but that they are often wrong is not. Clearly, then, the hypothetical perceiving point hits a problem. It seems to be at a rather distorted version of a point rather than at any actual place, so in what sense can it be said to have left the body or indeed to exist at all?

In my opinion all attempts to find something that could leave the body in an OBE fail on theoretical grounds. For that reason I prefer explanations of the OBE that do not involve anything leaving the body; psychological theories of the OBE, for example. If nothing leaves the body in an $\mathrm{OBE}$, then there is nothing to survive, and the OBE cannot be cited as evidence for survival.

However, I am quite prepared to believe that my arguments are wrong. One can read many philosophical works of twenty years ago expressing cogent reasons why one could never know that someone was dreaming, and could never answer such questions as how long dreams take, and whether babies dream. The arguments may have lost none of their force. However, there are few who would deny the importance of the progress in the psychology of dreaming that took place when objective correlates of dream reporting were discovered. And we have now been able to answer those awkward questions, at least to some extent. I mention that because I do believe that however convincing are my arguments against anything 
leaving the body, that is no justification for refusing to look at the evidence. It might still be the case that there was evidence that forced me to say, "I can't believe it, it can't be true, but the evidence suggests it." So is there any such evidence?

I shall consider any evidence that suggests something leaves the body. There are at least three types. First there is evidence that during OBEs people can see things at a distance without using the recognized senses (i.e., using extrasensory perception [ESP]). Secondly there is evidence that the double or astral body can be detected. And finally there is evidence from OBEs occurring near death. I shall consider each in turn.

In each case we may consider both anecdotal and experimental evidence. The spontaneous-case, or anecdotal, evidence is in some ways the most interesting and persuasive, but it is also the most problematic. In any case in which someone reports out-of-body vision, there are problems of collecting the reports, the vagaries and distortions of human memory, the difficulty of finding relevant witnesses and checking the details claimed, and the problems of eliminating expectation, sensory cues, and even fraud.

A case that illustrates all of these problems is that most famous of spontaneous OBE cases, the Wilmot case (Myers, 1903). Mr. Wilmot was travelling on a steamship from Liverpool to New York in 1863. As the story goes, his wife was worried because there was a severe storm at sea. She had an OBE and travelled to her husband's ship. There she saw him lying in his stateroom, and she went in and kissed him before returning home. Mr. Wilmot, meanwhile, was sleeping well for the first time in nine or ten days at sea, and dreamed he saw his wife come to his cabin. In the morning he was amazed to find that his own vision of her had been shared by his roommate, who chastised him for having a lady in his room at night. Apparently they had both seen Mrs. Wilmot, and she had seen them. On arriving home, Mr. Wilmot was asked by his wife if he had received a visit from her on the night in question (Myers, 1903).

This story sounds very convincing until you look a little further. It is now not possible to talk to the people concerned, of course, and I have found that there are no passenger lists or plans of the ship in existence. However, just reading the reports raises a host of questions. The whole story depends on the coincidence of $\mathrm{Mr}$. Wilmot's and his companion's visions with the experience of Mrs. Wilmot. However, we are told all three sides of the coincidence by none other than Mr. Wilmot himself, and he had been suffering from days of seasickness and sleeplessness at the time. That reduces its 
value, but worse still is that Mrs. Wilmot never reported having had an OBE at all. Mr. Wilmot reported that she was worried and seemed to go out to seek him. But in her own report she only alludes briefly to her "dream," and she gives no description of what she saw. She says she thinks she told her mother about it the next morning, but there is no report from her mother. By the time the case was written up in 1889 , the roommate was dead and unable to give his account. It seems to me that this case does not bear close scrutiny. I am not trying to say that it is worthless - it is a very interesting story just that it is not the kind of evidence that would convince a reasonable person of the existence of accurate out-of-body vision, or of the accurate detection of a person in the out-of-body state.

So where do we look for more solid evidence? We can look for more modern cases. I recently presented one myself (Blackmore, 1982d). A Canadian architect claimed to have visited London, and described in detail the houses he saw in a certain area of Fulham. Apparently he had asked an English colleague of his about that particular area of London, and the colleague had "proceeded to describe the character of the streets, the buildings, the style, the building setbacks and entrance yards - all exactly as I had seen them!" (p. 3). It seemed an exciting case and was easy enough to check, but as soon as I did I found that there are no houses even remotely fitting the description in Fulham. Like so many other cases, this one does not seem to stand up to examination. The main lesson we have to learn, I believe, is that nothing has changed. A hundred years has not produced the evidence, and yet we go on looking for it in the same old ways. Will we never learn?

Some would say that the experimental evidence is far stronger. There is a little such evidence from early this century. For example, hypnotized mediums were asked to "exteriorize" their doubles, and the doubles were then supposed to be able to see things presented before their eyes, while the mediums could not see them. The same was done with smells, tastes, and touch, but the most elementary precautions against normal perception were not taken, and those experiments cannot be considered seriously (see Blackmore, 1982a).

For a long time nothing along experimental lines was attempted, and then twenty years ago laboratory research on OBEs began. Charles Tart $(1967,1968)$ was the first to test a subject who claimed to be able to have an OBE at will in the laboratory. Tart set up an experiment in which the subject was to lie on a bed, above which was a shelf with a five-digit number on it. The subject's aim was to see the number when out of his or her body. Robert Monroe (well 
known for his book Journeys Out of the Body, 1971), was the subject on nine occasions but failed to see the number at all. Then a girl referred to as Miss $Z$ tried and, on her fourth and last attempt, managed not only to have an OBE but to see the number and report it correctly. That seemed to be a great breakthrough. One of the most persistent problems in parapsychology is that results are easy to collect, but terribly unreliable. Here it seemed that although it was hard to get anyone to see the number, once seen it was seen correctly. That would be a great advance if it could be repeated and would put outof-body vision in a class altogether different from "normal" ESP. The hope, however, was short lived. Miss $Z$ was unable to come to the laboratory any more, and no other subject has ever achieved that accuracy again. It is also a pity that the number was in the same room as the subject, because however unlikely it seems to be (and Tart $[1967,1968]$ has argued that it is very unlikely), it is possible that she saw the number normally. If the result cannot be repeated, we shall never know for certain.

Subsequent experiments of the same kind (e.g., Osis, 1974; Mitchell, 1981; Osis and McCormick, 1980) have produced results much like so many others in parapsychology. That is, they are sometimes suggestively above chance, but not much more than that.

Those experiments raise an additional tricky question about the interpretation of out-of-body vision. Even if people could see at a distance during OBEs, that is not necessarily evidence that something leaves. After all, they could be using ESP. The ESP problem has worried parapsychologists since modern research on OBEs began some twenty years ago. The problem is how to distinguish between ESP and out-of-body vision. In some sense, it is logically impossible. ESP is defined negatively and therefore can never be ruled out. However, some ingenious experiments have been designed to try.

Karlis Osis (1975) designed the "optical-image device": a box containing a mass of pictures, colored filters, and mirrors. Looking in through the lid, one would see all of these in a jumble, but looking in through the viewing hole, one sees a particular picture of a certain color appearing in one of four quadrants. Osis's subject, Alex Tanous, was asked to try to travel, during an OBE, to a distant room and to look into the optical-image device. The idea was that if he "saw" the right picture, he must have been using localized viewing rather than generalized ESP. In fact the results were inconclusive. Osis (1975) claimed that they supported the hypothesis of localized viewing, but it was only by marginal effects. And in any case one 
could never be sure that ESP could not operate like localized viewing. We simply know too little about the workings of ESP.

So what are we to conclude? I genuinely believe that the fairest and most reasonable interpretation is to say that out-of-body vision has been tested and has not been found. Here many others certainly disagree with me, but I can only present the conclusion that seems to me to fit the evidence best.

One last thing to point out is how very little the research has changed in all these years. Nearly one hundred years ago Frederic W.H. Myers (1903) had a good idea of what would be considered acceptable evidence. Psychical researchers twenty and thirty years after his death were still looking for it and using basically similar methodology. In spite of advances in experimental design, we are still using it today; that is, testing whether people can see some concealed object or target at a distance while having an OBE. It may be considered a mark of a progressive science that the problems it tackles change as it develops. In Imre Lakatos's (1978) terms, there is a progressive problemshift. By this criterion, research on OBEs has not progressed at all in a hundred years. I think it is about time it did.

Much the same criticism can be leveled at research of the second type; that is, the attempts to detect the double. Early this century the doubles of hypnotized mediums were asked to sit on weighing scales and to ring electric bells and were even photographed (see Blackmore, 1982a). However, when the research methods were improved, the early exciting results disappeared. More recently, sophisticated apparatus has been used to try to detect the presence of a double or astral body while a subject is having an OBE in a different room. The most notable of that research was a long series with the subject Blue Harary at the Psychical Research Foundation. Humans, animals, and a mass of different physical systems were used, but the final conclusion was, "Overall, no detectors were able to maintain a consistent responsiveness of the sort that would indicate any true detection of an extended aspect of the self" (Morris et al., 1978, p. 1).

There have been some indications of detectability. For example, in one of the experiments Blue Harary was apparently able to influence the behavior of one of his two pet kittens. The kitten miaowed and moved significantly less when Harary was having an $\mathrm{OBE}$ as compared with control periods. Some have seen that as evidence that the double left the body, but it depends on a small statistical effect with one of two kittens, and it was not repeatable. Also there still remains the problem that it could have been ESP or psychokinesis between man and cat. 
Osis and Donna McCormick (1980) claimed to have detected Alex Tanous's out-of-body presence while he was engaged in a perceptual task. Strain gauges were placed near the optical-image device, and they showed greater activation on trials when he correctly perceived the target in the box than on those when he was wrong. They argued that in some sense he was more exteriorized on those trials and unintentionally affected the strain gauges. I have pointed out (Blackmore, 1981) that overall the results of the perceptual task were equal to those expected by chance. So if he was "really there" on hit trials, there must have been psi-missing on the other trials. Julian Isaacs (1981) has also noted problems with the apparatus used.

Many people would argue with my conclusion that the evidence is not good enough. For example D. Scott Rogo (personal communication, 1982) has argued that if $\mathrm{I}$ had been at the experiment with the kitten and seen its behavior, I would "know" that it had detected Harary's presence. I can only say that I wish I had been there to see for myself. But going on the basis of published findings, I think the only fair conclusion is that of Robert Morris, et al. (1978). The out-of-body "whatever it is" seems to be undetectable as yet.

The third type of evidence concerns OBEs occurring near death. It has long been known that people approaching death report visions of many kinds, and these visions can include OBEs. Research into near-death experiences (NDEs), from Raymond Moody's (1975) pioneering work to more recent research by Kenneth Ring (1980) and Michael Sabom (1982), has made it clear that the OBE is an important and frequent constituent of the NDE. Whether OBEs occurring near death are the same phenomenon as OBEs occurring under other circumstances is not yet clear. However, they are certainly similar enough to treat as one until we have any evidence to the contrary.

Other components of the "typical" NDE include roaring noises in the ears, the experience of rushing along a tunnel (like my tunnel of trees), seeing a light at the end of the tunnel, meeting with dead relatives or religious beings, and glimpsing another world. The big question is, of course, whether all NDEs could be creations of the dying brain in its last moments, or whether they are what they seem, a prelude to, and glimpse of, the world to come.

This is not the place to consider such evidence in detail, but I should point out the few suggestions that something paranormal may be involved. In particular Sabom (1982) has presented evidence that people having NDEs while unconscious and unresponsive have correctly reported details of medical procedures and apparatus that 
they could not possibly have known about. In addition he found that cardiac patients who had not had an NDE were unable to imagine such scenes in the same accurate and convincing way. However, these patients did not have the auditory and other information that may be available to people coming close to death, so the comparison is not as fair as it first appears. The importance of the additional auditory information is something to be determined by future research.

I believe it is too early to say whether near-death experiencers can actually see things paranormally. There is certainly evidence in that direction, but it is not clear-cut, and we shall have to await the results of future work to find out whether or not it stands the test of time. However, it may be useful at this stage to consider what sort of evidence would be convincing. First, there could be better evidence for paranormal perception during NDEs. If that is obtained, then I would be forced to reconsider my position. But it would still be a long step to concluding that OBEs provide evidence for survival. We would still have to deal with the thorny question of ruling out ESP as an alternative explanation, even to conclude that something leaves the body. And even that is only the first step.

The second is to ask whether that "something" could survive death or operate without a physical body. One way of approaching the problem is to ask whether NDEs can occur when brain activity has ceased. If a complex structured experience occurs, involves the paranormal acquisition of information, and could be shown to occur at a time when there was little or no brain activity, then that would strongly challenge any purely cognitive or psychological account of the experience. The ability to collect that kind of evidence is in sight, and it would be important if found. However, I must add that even that still would not get round the problem that anyone who can tell us about his or her NDE was not actually dead at the time. Awkward problems like that beset the search for survival evidence at every turn.

I have now considered, albeit very briefly, the kinds of evidence that might persuade one that the OBE was evidence for survival, and the only verdict I can reach is "unproven." The evidence, as it stands at the moment, is not sufficient to persuade me to reject my arguments against the possibility of something leaving the body, or of there being a double, astral body, spirit, or soul to survive. Why then do so many people disagree with me?

I think there are two reasons. The first I have already discussed; that is, the convincing nature of OBEs to those who have them. 
But I think there is a more important reason. That is that the alternatives presented are always so feeble. All too often the choice presented is between "something leaves - wow - we have a spirit - everything is exciting" and "it's all in the mind, or just imagination." It is that "just" that infuriates me. Imagination is far too vast and exciting a world to be denigrated with the word "just." But the psychological theories of the OBE are very weak, as pointed out for example by Rogo (1983). It is therefore not surprising that people don't take them seriously. What we need is a viable and exciting alternative to the "something leaves" theories. We could then make a reasoned choice between them.

The test of a good theory is, in my opinion, that it leads to progressive and productive research. Looking back over the research of the last hundred years, it is crystal clear that it has not progressed. The same questions are being asked, the same awkward problems faced, and the same difficulties tackled now as a hundred years ago. I believe it is because the whole research program is fundamentally misguided and inappropriate.

We need to start all over again. Let us make some new assumptions, ask some new questions, and see where they lead. If that attempt fares as badly as previous research, we can soon abandon it.

Let us assume for the moment that all experiences depend upon a functioning brain, that there is no soul, spirit, astral body, or double, and that nothing leaves the body in an OBE. Why then do people have OBEs? Indeed, why do they have NDEs and profound mystical experiences? And why are people so very moved by these experiences, as clearly they are?

Let us start by looking at the OBE as something telling us a lot about brain function, rather than the reverse. In the psychology of perception a great deal has been learned from the study of visual illusions (e.g., Gregory, 1966). When the visual system concludes that one of two equal-length lines is longer, for example in the Ponzo illusion, that does not tell us that the brain has gone wrong, but rather it tells us how the visual system draws an incorrect inference from perfectly reasonable processes. In other words the illusion tells us about those processes.

Similarly the OBE may tell us about how we normally structure our perception and our images of ourself. The process of perception involves building models of a world "out there" viewed by a stable self. If under certain circumstances our brain concludes that "we" are outside our bodies, I think that tells a lot about what it means to think we are inside. Most of the time most of us think we are in 
our head, behind our eyes, or in some other convenient spot within the body. Wherever it is, that does not tell us that there is a soul or something at that spot, rather it tells us that we have chosen to organize our perception and self image that way, as a convenience in our construction of experience. Why then should people sometimes make the odd decision that they are outside the body?

Normally we create a stable model of ourselves that includes our body position and immediate surroundings, seen from our own "personal viewpoint." The whole process of perception is one of modeling, and as we move, see, and hear, we update our model of "reality" to accommodate changing input. We also use information from memory, from the "cognitive map" of the world. For example, when you see a wall in your own home, you may easily be able to imagine the room behind it, even though you cannot see it.

The reason we maintain a "personal viewpoint" consistent with the body's position is that sensory input keeps on confirming it. However, if sensory input is cut off, or drastically reduced, we may go on building models, but they cannot be tied to input or to the correct body position. The result is that the model may drift from the correct viewpoint, and an OBE occurs.

In that unusual state, if you try to work out where "you" are, you have none of the normal mechanisms operating that will tell you. In an attempt to, as it were, regain normality, you may imagine the position you know yourself to be in and your own body sitting, standing, or whatever it was doing. That will provide a relevant image, but the coordination is lost and the result is that you seem to be wherever you imagined the scene from.

An interesting question raised is why so many OBErs find themselves seeming to be above and behind the level of the head. A possible answer is that that is a most convenient place from which to structure imagined places. In particular, if you try to imagine any familiar room, you may well find that you do so from just such a position because it gives a better overall view than normal head height. That possibility could clearly be tested.

The idea that the OBEr's brain constructs a world to explain what it perceives leads to a lot of interesting conclusions. First it becomes clear why the occultists refer to a "thought-created world." That is precisely what it is. And you can travel in it at any speed you can imagine travelling. Sylvan Muldoon (Muldoon and Carrington, 1929) described the three travelling speeds in the "astral plane," and those conform closely to the ways in which we can manipulate visual images in our cognitive map (that is, the mental map we build from 
our perceptual experience). Try to imagine, for example, travelling from your home to work or to a friend's house. You will probably find that you can either see every detail as you would when walking, or can skim the streets very fast, or can just start at one and end at the other. Those are almost identical to the "astral" travelling speeds.

We also know a lot about the sorts of errors made in OBEs. People may not see things that are there, may add likely objects like chimneys or doors and windows that aren't actually there, and so on. That is exactly what we find in the cognitive map. Imagine the same route as before, and look at a certain building as you pass by. How many windows has it or how many steps up to the door? You may well find that you can "see" the windows or steps but are unable to count them. That is probably because your image is not really like a picture at all. It is a representation of what you know about the building. You know it has windows so you "see" windows, but you have never counted them, so the number of windows is not represented. I am convinced that the astral world is just like that. It is a world of mental representations, and that is why it has all the qualities of the cognitive map. The occultists hit the nail on the head with their expression "thought-created world."

Another interesting point concerns the end of the OBE. Typically it ends suddenly, with a snap back to the body or even a momentary "blanking of consciousness" (Crookall, 1961). That is just what we would expect on this model. If at some point sensory input starts to reassert itself, the normal mechanisms will reinstate the usual viewpoint. One cannot sustain an in-between state, seeing both from the normal position and from the out-of-body position. The normal one will always win, so back one comes with a rush. That may also account for some of the apparent discreteness of the OBE.

I would also like to say more about the tunnel. It seems there are good reasons why a tunnel should appear. It is known to be a common form in drug-induced hallucinations (Siegel, 1977; Drab, 1981) and of course in NDEs and OBEs. One possible reason is that concentric rings in the visual field are represented by straight lines in certain parts of the visual cortex. In a hallucinating state there may be electrical noise in the cortex that runs in straight lines. The effect is to produce the appearance of concentric rings, or a tunnel, as though being perceived. Any other images at the same time are seen in this perspective. The same argument applies to tunnels in migraine, which is certainly associated with cortical noise.

Another idea works by analogy with visual constancy mechanisms. We see a plate as round regardless of its angle to us, and it stays the 
same size as it approaches us, because of constancy mechanisms. Also, everything we see is in perspective, and that has to be counteracted so that straight lines appear straight. However, if we applied this same "correction" to internally produced noise, it would have the reverse effect and produce a tunnel. That idea needs testing, but the important point is that there are various psychological reasons why we might expect tunnel forms, and these need no recourse to astral bodies or spirit worlds.

The crucial point is clearly whether all these speculations can lead to any testable predictions or not. I believe they most certainly can, and I will give just a couple of examples.

In the state $I$ described as necessary for an OBE, anything imagined appears "real." If one imagined the room as from one's actual position, it should seem real whether or not one's eyes were open. I have had the experience of seeming to see with my eyes closed in a state that felt like that necessary for an OBE. So in a recent survey I asked this question: "Have you ever seemed to see with your eyes closed?" OBErs answered "yes" to the question more of ten than did control subjects. More generally, people who reported OBEs also reported all sorts of hallucinations, and $I$ have found that in a random sample of people, among students, and among schizophrenics (Blackmore, 1982b, 1982c, 1984; Blackmore and Harris, 1982).

If the OBE is basically a product of the imagination, then we should expect people with better imagery to be more likely to have OBEs. That idea has led to a lot of controversy, and in fact it seems that OBErs have no more vivid imagery (Irwin, 1981), but there is good evidence that they can more easily become immersed in an experience to the exclusion of the outside world (Irwin, 1981). This research is still in its infancy, but already it seems to be producing far more in the way of reliable findings than the paranormally based research has ever done.

These are just a few of the hints that it is worth pursuing the idea of the OBE as a product of the imagination rather than as something leaving the body. It is too early to boast that we have gotten very far, but I am convinced it is worth following this route. If this approach is correct, it implies that there is no astral body, other than one invented by the imagination, and nothing travels in the OBE. Correspondingly there is nothing to survive, and the OBE cannot be seen as evidence for survival. Therefore the answer to my original question is "No."

But we mustn't fall into the trap of saying that the OBE is "just imagination." Rather, it provides a privileged glimpse into the 
structure of imagination. We have scarcely begun to look into this world, and the sooner we start to understand it the better. Understanding the OBE in these terms, and abandoning the search for paranormal aspects, may be just a beginning.

The next steps are towards understanding NDEs and mystical experiences. At the moment we have no science of mystical experience. Theologians study the implications for theology, psychiatrists denigrate them to abnormality, and doctors are only interested if they relate to pathology, and parapsychologists if they involve the paranormal. A few psychologists have made just a beginning (e.g., Maslow, 1971; Neher, 1980). I hope we may see the future psychological study of the OBE leading to a larger study of mystical experience; one that may finally give some non-religious and non-medical insight into those experiences that to so many people are the most important thing in their lives.

We have a long way to go, but the first step is to say that the OBE is not "just" imagination. It is imagination, and that may be quite the most exciting thing it could be.

\section{REFERENCES}

Badham, P., and Badham, L. Immortality or Extinction? London: MacMillan, 1982.

Blackmore, S.J. On the extrasomatic localization of $O B$ projections.

Correspondence. Journal of the American Society for Psychical Research, 1981, 75, 365-366.

Blackmore, S.J. Beyond the Body. London: Heinemann, 1982a. Blackmore, S.J. Have you ever had an OBE?: the wording of the question. Journal of the Society for Psychical Research, 1982b, $51,292-302$.

Blackmore, S.J. OBEs, lucid dreams and imagery: two surveys. Journal of the American Society for Psychical Research, 1982c, 76, 301-317.

Blackmore, S.J. Parapsychology - with or without the OBE? Parapsychology Review, 1982d, 13(6), 1-7.

Blackmore, S.J. A postal survey of OBEs and other experiences. Journal of the Society for Psychical Research, 1984, in press.

Blackmore, S.J., and Harris, J. OBEs and perceptual distortions in schizophrenics. Presented at the Society for Psychical Research/ Parapsychological Association Joint Centennial/Jubilee Conference, Cambridge, August 1982. 
Crookall, R. The Study and Practice of Astral Projection. London: Aquarian Press, 1961.

Drab, K.J. The tunnel experience: reality or hallucination? Anabiosis, $1981,1,126-152$.

Gabbard, G.O., Twemlow, S.W., and Jones, F.C. Differential diagnosis of altered mind/body perception. Psychiatry, 1982, 45, 361-369.

Green, C.E. Out-of-the-Body Experiences. London: Hamish Hamilton, 1966.

Hart, H. ESP projection: spontaneous cases and the experimental method. Joumal of the American Society for Psychical Research, 1954, 48. 121-146.

Irwin, H.J. Some psychological dimensions of the OBE. Parapsychology Review, 1981 12(4), 1-6.

Isaacs, J. On kinetic effects during out-of-body projection. Correspondence. Journal of the American Society for Psychical Research, 1981, 75, 192-194.

Kohr, R.L. A survey of psi experiences among members of a special population. Journal of the American Society for Psychical Research, 1980, 74, 395-411.

Lakatos, I. The Methodology of Scientific Research Programmes. Philosophical Papers. Vol. I. Cambridge: Cambridge University Press, 1978.

Maslow, A. The Farther Reaches of Human Nature. London: Viking Press, 1971.

Mitchell, J.L. Out-of-Body Experiences: A Handbook. Jefferson, N.C.: McFarland, 1981.

Monroe, R.A. Journeys Out of the Body. New York: Doubleday, 1971.

Moody, R.A. Life After Life. Covington, Ga.: Mockingbird, 1975. Morris, R.L., Harary, S.B., Janis, J., Hartwell, J., and Roll, W.G. Studies of communication during out-of-body experiences. Journal of the American Society for Psychical Research, 1978, 72, 1-22.

Muldoon, S., and Carrington, H. The Projection of the Astral Body. London: Rider, 1929.

Myers, F.W.H. Human Personality and Its Survival of Bodily Death. London: Longman's, Green \& Co., 1903.

Neher, A. The Psychology of Transcendence. Englewood Cliffs, N.J.: Prentice-Hall, 1980.

Noyes, R., and Kletti, R. Depersonalization in the face of lifethreatening danger: a description. Psychiatry, 1976, 39, 19-27.

Osis, K. Perspectives for out-of-body research. In W.G. Roll, R.L. Morris, and J.D. Morris (Eds.), Research in Parapsychology, 1973. Metuchen, N.J.: Scarecrow Press, 1974. 
Osis, K. Perceptual experiments on out-of-body experiences. In W.G. Roll, R.L. Morris, and J.D. Morris (Eds.), Research in Parapsychology, 1974. Metuchen, N.J.: Scarecrow Press, 1975.

Osis, K. Insiders' views of the OBE: a questionnaire survey. In W.G. Roll (Ed.), Research in Parapsychology, 1978. Metuchen, N.J.: Scarecrow Press, 1979.

Osis, K., and McCormick, D. Kinetic effects at the ostensible location of an out-of-body projection during perceptual testing. Journal of the American Society for Psychical Research, 1980, 74, 319-329.

Palmer, J. A community mail survey of psychic experiences. Journal of the American Society for Psychical Research, 1979, 73, 221-252.

Ring, K. Life at Death. New York: Coward, McCann \& Geoghegan, 1980.

Rogo, D.S. Mind Beyond the Body. New York: Penguin, 1978.

Rogo, D.S. Psychological models of the out-of-body experience. Journal of Parapsychology, 1982, 46, 29-45.

Rogo, D.S. Leaving the Body. Englewood Cliffs, N.J.: PrenticeHall, 1983.

Rushton, W.A.H. Letter to the editor. Journal of the Society for Psychical Research, 1976, 48, 412-413.

Sabom, M. Recollections of Death. New York: Harper and Row, 1982.

Siegel, R.K. Hallucinations. Scientific American, 1977, 237, 132-140.

Siegel, R.K. The psychology of life after death. American Psychologist, 1980, 35, 911-931.

Tart, C.T. A second psychophysiological study of out-of-the-body experiences in a gifted subject. International Journal of Parapsychology, 1967, 9, 251-258.

Tart, C.T. A psychophysiological study of out-of-the-body experiences in a selected subject. Journal of the American Society for Psychical Research, 1968, 62, 3-27.

Requests for reprints to:

Dr. S.J. Blackmore

Brain and Perception Laboratory

University of Bristol

Bristol, England 